\title{
Implementing Metal-Organic Frameworks for Natural Gas Storage
}

\author{
Eyas Mahmoud ${ }^{1, *}$, Labeeb Ali ${ }^{1}$, Asmaa El Sayah ${ }^{1}$, Sara Awni Alkhatib ${ }^{1}$, Hend Abdulsalam ${ }^{1}$, \\ Mouza Juma ${ }^{1}$ and Ala'a H. Al-Muhtaseb ${ }^{2}$ \\ 1 Department of Chemical and Petroleum Engineering, United Arab Emirates University, Al-Ain 15551, UAE \\ 2 Department of Petroleum and Chemical Engineering, Sultan Qaboos University, Muscat 123, Oman \\ * Correspondence: emahmoud@uaeu.ac.ae
}

Received: 16 June 2019; Accepted: 2 August 2019; Published: 4 August 2019

\begin{abstract}
Methane can be stored by metal-organic frameworks (MOFs). However, there remain challenges in the implementation of MOFs for adsorbed natural gas (ANG) systems. These challenges include thermal management, storage capacity losses due to MOF packing and densification, and natural gas impurities. In this review, we discuss discoveries about how MOFs can be designed to address these three challenges. For example, $\mathrm{Fe}(\mathrm{bdp})\left(\mathrm{bdp}^{2-}=1,4\right.$-benzenedipyrazolate) was discovered to have intrinsic thermal management and released $41 \%$ less heat than HKUST-1 (HKUST $=$ Hong Kong University of Science and Technology) during adsorption. Monolithic HKUST-1 was discovered to have a working capacity $259 \mathrm{~cm}^{3}(\mathrm{STP}) \mathrm{cm}^{-3}(\mathrm{STP}=$ standard temperature and pressure equivalent volume of methane per volume of the adsorbent material: $\mathrm{T}=273.15 \mathrm{~K}, \mathrm{P}=101.325 \mathrm{kPa}$ ), which is a $50 \%$ improvement over any other previously reported experimental value and virtually matches the 2012 Department of Energy (Department of Energy = DOE) target of $263 \mathrm{~cm}^{3}(\mathrm{STP}) \mathrm{cm}^{-3}$ after successful packing and densification. In the case of natural gas impurities, higher hydrocarbons and other molecules may poison or block active sites in MOFs, resulting in up to a $50 \%$ reduction of the deliverable energy. This reduction can be mitigated by pore engineering.
\end{abstract}

Keywords: metal-organic frameworks; thermal properties; mechanical properties; impurities; ANG; natural gas storage; methane storage; adsorption

\section{Introduction}

In 2017, 4.6219 billion tons of oil equivalent were consumed for transportation and other uses [1]. Fossil fuel use resulted in the emission of 33 billion tons of $\mathrm{CO}_{2}$ [2-4]. In addition to $\mathrm{CO}_{2}$ emission, the use of fossil fuels resulted in more than the doubling of the price of petroleum since 1998 [5-7]. European Union member states committed to a $40 \%$ reduction in greenhouse gas emissions, such as $\mathrm{CO}_{2}$ in the 2030 Climate and Energy Framework [8]. In addition, many countries such as the United Kingdom, France, Germany, and parts of the United States and China plan to ban new gasoline vehicles sales by 2040 [9]. To address the sustainability and environmental impacts of petroleum as a transportation fuel, renewable energy sources such as hydrogen and biomass are being developed [10-12]. At the time when others are looking into alternatives and into making them practically and economically viable, natural gas is a good alternative or substitute to petroleum as a transportation fuel because it has a lower cost, is available, and releases $270 \mathrm{~g}$ of $\mathrm{CO}_{2}$ per mile as compared to the $450 \mathrm{~g}$ of $\mathrm{CO}_{2}$ per mile when gasoline is used as a fuel [13]. As of April 2019, there were 27,414,984 natural gas vehicles (NGVs) and 32,211 natural gas fueling stations [14].

Natural gas and methane can be stored and delivered as compressed natural gas (CNG), liquified natural gas (LNG), and adsorbed natural gas (ANG). In the case of CNG, natural gas is stored at a pressure of 250 bar (3500 psi) in low-cost steel tanks and delivered as a fuel. CNG has an energy density 
of $9.2 \mathrm{MJ} \mathrm{L}^{-1}$, which is $70 \%$ less than that of gasoline $[2,15]$. However, carrying an extremely pressurized tank raises safety concerns in vehicles in the case of accidents and has an energy cost associated with compression. Furthermore, CNG, which is the established and predominant technology for NGVs, has a driving range of 350-450 km as compared to $400-600 \mathrm{~km}$ for gasoline-powered vehicles [16]. Based on this, there is a need to develop gas storage technology beyond that which is already established in real life applications. Further improvements in natural gas storage for NGV technology should seek to improve driving range to decrease time at the pump and the corresponding number of required tank recharges. Increasing driving range would be helpful to implement the technology in areas where natural gas filling stations are not as abundant. In addition, the CNG tank that holds the fuel takes up cargo space and technological advancements that decrease the volume of the natural gas fuel tank are beneficial. Another approach to store natural gas is LNG, which has an energy density of $22.2 \mathrm{MJ} \mathrm{L}^{-1}$. Some drawbacks of LNG are the energy and cost associated with liquefaction $\left(-162^{\circ} \mathrm{C}\right)$, which present major technological obstacles $[17,18]$ Lastly natural gas can be stored as ANG. Fairly large volumetric capacities of 4-6 MJ L $\mathrm{L}^{-1}$ at pressures of around 35 bar at room temperature for different adsorbents were achieved [19]. The presence of sorbent materials in high pressure tanks reduces the pressure requirement of the tanks, making storage and delivery safer and allows for the use of single-stage compressors. ANG may increase the driving range and decrease the volume required of the fuel tank to achieve a specific driving distance as compared to CNG [20].

For ANG, different classes of adsorbents were designed and tested for natural gas such as activated carbons, zeolites, porous coordination polymers (PCPs) [21], and metal-organic frameworks (MOFs) [22-24]. These materials have to be able to adsorb and desorb natural gas, which consists of more than $90 \mathrm{~mol}$. \% methane. In the case of activated carbons, volumetric methane capacities are in the range of 100-170 $\mathrm{cm}^{3}$ (STP) $\mathrm{cm}^{-3}$ [25-28]. Zeolites typically have methane uptakes below $100 \mathrm{~cm}^{3}$ (STP) $\mathrm{cm}^{-3}$ [23]. $\mathrm{Cu}(\mathrm{BPY})_{2} \mathrm{SiF}_{6}$ (BPY,4,4-bipyridine), a PCP, has a gravimetric methane uptake of $146 \mathrm{~cm}^{3}$ (STP) $\mathrm{g}^{-1}$ at $298 \mathrm{~K}$ and $36 \mathrm{~atm}$ [29]. MOFs were found to have better methane storage capability (more than $170 \mathrm{~cm}^{3}(\mathrm{STP}) \mathrm{cm}^{-3}$ ) in part due to their crystallinity, stability, organic functionality, and porosity [30-32].

In 2012, the US Department of Energy (DOE) set new targets for methane storage to achieve a volumetric storage capacity of $350 \mathrm{~cm}^{3}$ (STP) cm $\mathrm{cm}^{-3}$, gravimetric storage capacity of $0.5 \mathrm{~g}\left(\mathrm{CH}_{4}\right) \mathrm{g}^{-1}$ at room temperature, and capacity of $263 \mathrm{~cm}^{3}$ (STP) $\mathrm{cm}^{-3}$ after successful packing and densification [33]. This target for methane storage materials corresponds to a gravimetric capacity of $50 \mathrm{wt} . \%$ and a volumetric capacity of $250 \mathrm{~g} \mathrm{~L}^{-1}$.

MOFs are being designed to meet these storage targets through the variation of properties such as pore size [34], pore architecture [35], and hydrophobicity [36]. Furthermore, the building-blocks of MOFs may be varied resulting in changes in the nature of organic ligands $[37,38]$, including ligand length [38] and functionalization [39,40], and metal center [41] to improve working capacity of MOFs for natural gas and methane storage [42]. To this end, strategies such as breathing MOFs can also be used [43-45]. One benchmark MOF material is HKUST-1, which is composed of $\mathrm{Cu}_{2}(-\mathrm{COO})_{4}$ secondary building units (SBUs = secondary building units) with a paddle wheel shape. It has a surface area of $1800 \mathrm{~m}^{2} \mathrm{~g}^{-1}$. For HKUST-1, the amount of methane adsorbed and desorbed between 65 bar and $5 \mathrm{bar}$, or the deliverable capacity, is $190 \mathrm{~cm}^{3}$ (STP) $\mathrm{cm}^{-3}$ [46-48]. The reported deliverable capacity for HKUST-1 is $153 \mathrm{~cm}^{3}$ (STP) $\mathrm{cm}^{-3}\left(109 \mathrm{~g} \mathrm{~L}^{-1}\right)$ at 35 bar. HKUST-1 is available as Basolite C300 in the market [24,49]. An isoreticular MOF, IRMOF-6 (IRMOF = isoreticular MOF) showed a gravimetric uptake of $205 \mathrm{~cm}^{3}$ (STP) $\mathrm{g}^{-1}$ and volumetric uptake of $155 \mathrm{~cm}^{3}$ (STP) $\mathrm{cm}^{-3}$ at $36 \mathrm{~atm}$ and $298 \mathrm{~K}$. MOF-905 has a value rivaling of $203 \mathrm{~cm}^{3}$ (STP) $\mathrm{cm}^{-3}\left(145 \mathrm{~g} \mathrm{~L}^{-1}\right)$ at 80 bar and $298 \mathrm{~K}$ [50]. Other MOFs developed are aluminum MOFs termed as MOF-519 and MOF-520, composed of $\mathrm{Al}_{8}(\mathrm{OH})_{8}(-\mathrm{COO})_{16}$ SBUs joined together with triangular BTB (BTB = benzene tribenzoate) linkers. MOF-519 has a narrowed size compared to MOF-520 with partially uncoordinated B2B (B2B = back to back) linkers and a Brunauer-Emmett-Teller (BET) surface area of $2400 \mathrm{~m}^{2} \mathrm{~g}^{-1}$ which allows it to adsorb $259 \mathrm{~cm}^{3}$ (STP) $\mathrm{cm}^{-3}$ methane with a high delivery capacity of $210 \mathrm{~cm}^{3}$ (STP) $\mathrm{cm}^{-3}$ at 65 bar and $298 \mathrm{~K}$ [51]. A plethora of other MOFs were 
tested as described in review papers [52-57] and others publications [58,59]. However, MOFs such as HKUST-1 and others do have limitations when implemented for natural gas storage.

For the implementation of MOFs for natural gas or methane storage, a variety of challenges arise, which can decrease uptake and deliverable capacity by up to 50\%. As discussed by Mason and others, these challenges in implementation include thermal management, pelletization or densification losses in storage or deliverable capacity, and natural gas impurities (Figure 1) $[24,57,60]$. These problems can be addressed from a system or materials design perspective [61-63]. Here, we provide a detailed description of how these problems can be addressed through materials design to decrease cost, weight, and space. The known thermal, and mechanical properties of MOFs are considered in terms of a total system perspective [64]. In the ANG system, adsorption of gas is an exothermic process and desorption is endothermic, which leads to potentially large changes in temperature that reduce the amount of gas that can be stored and delivered [65]. We discuss how MOFs which undergo phase changes can effectively manage heat. In the case of pelletization or densification losses on natural gas uptake and deliverable capacity, the mechanical properties of the materials should be considered to avoid pore collapse [66]. We detail how strategies' functionalization of MOFs can increase the bulk modulus and improve mechanical properties. In addition, natural gas impurities may block active sites and significantly decrease uptake and negatively impact cyclability [57]. Effective MOF design strategies to mitigate these problems through pore engineering are discussed.

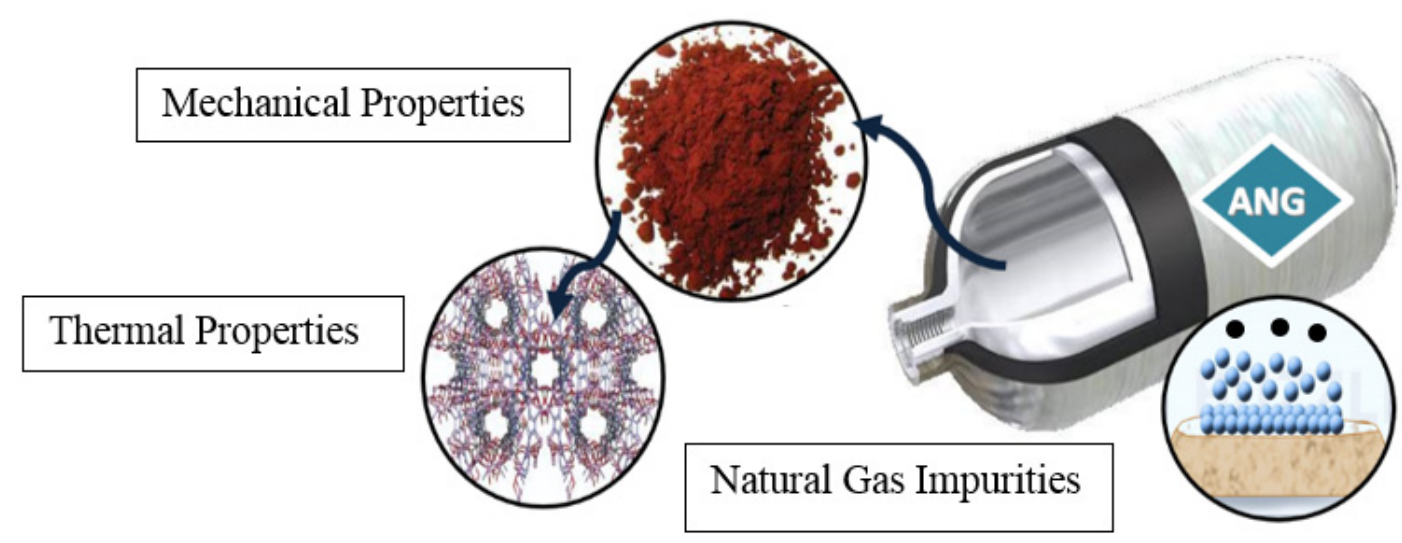

Figure 1. Challenges associated with the implementation of MOFs for natural gas storage.

\section{Thermal Properties}

In the ANG system, adsorption of gas is an exothermic process, which leads to a potentially large increase in temperature that reduces the amount of gas that can be adsorbed [65]. In addition, desorption of gas is endothermic and can also contribute to a decrease in temperature, decreasing the amount of gas that can be desorbed [67]. Therefore, during the fueling of the tank, the adsorbent bed will release heat and cool during discharge. Fueling the tank at a faster rate, which is often desirable to decrease the time at the tank, leads to even greater temperature changes. During normal driving, experiments have shown that a prototypical carbon tank can cool as much as $37^{\circ} \mathrm{C}$, reducing methane storage capacity by $20 \%$, as compared to the isothermal tank [67]. Another negative consequence of this effect is that if the temperature of the tank exceeds the maximum temperature that the tank can tolerate, then the tank would no longer be able to withstand the pressure and there may be a release of the fuel. From a systems-level perspective, thermal management may be addressed by the incorporation of a heat exchanger in the system, changing the material of construction, and the geometry of the tank. However, this results in a trade-off between cost, weight, and available space.

Another approach to address thermal management is through material design [24,68]. Important properties of MOFs that affect thermal management are heat capacity, decomposition temperature, and thermal conductivity. High heat capacities of MOFs decrease the magnitude of temperature changes during the charging and discharging of the tank. Specific heat capacities of MOF-5, Cu-BTC 
(BTC = benzene-1, 3, 5-tricarboxylate), Fe-BTC, MOF-177 and MIL-53 (Al) (MIL = Materials Institute Lavoisier) were reported over a wide temperature range [69]. The heat capacities of these MOFs at $300 \mathrm{~K}$ are in the range of 0.66 to $0.92 \mathrm{~J} \mathrm{~g}^{-1} \mathrm{~K}^{-1}$. Fe-BTC had the highest heat capacity of the materials studied, followed by MIL-53, MOF-177, and MOF-5. The heat capacities of these MOFs were found to monotonically increase with temperature. Additional thermal analysis and heat capacity studies of Mg-BTC, Co-BTC, Mn-BDC (BDC=1,4-benzenedicarboxylate), MOF-36, and IR-MOF-1 indicated that these MOFs have comparable heat capacities as other solids such as zeolites, carbon nanotubes, and other minerals [70]. Mg-BTC was found to have the highest heat capacity of around $1.4 \mathrm{~J} \mathrm{~g}^{-1} \mathrm{~K}^{-1}$ followed by Co-BTC. Another thermal property to note is the decomposition temperature. Some MOFs were found to not significantly decompose at temperatures as high as $300{ }^{\circ} \mathrm{C}$, while other MOFs such as HKUST- 1 decompose at temperatures of around $240{ }^{\circ} \mathrm{C}$. For MOFs, thermal stability is determined by the coordination number and local coordination environment and is not determined by the topology of the framework. It is important to note that the heat capacities of MOFs that have been reported in literature are limited and more experimentally determined heat capacity data is needed. This new data should be related to the structure of the MOF.

The structure of MOFs can be designed to increase the thermal conductivity of the MOF to obtain favorable heat transfer properties for natural gas storage and delivery. High thermal conductivities allow for faster dissipation of heat from the system. By decreasing the pore size of MOFs, the thermal conductivity can be simultaneously increased [71]. However, it must be noted that there exists an optimal pore size for gas storage. Therefore, the effectiveness of this strategy depends on what the optimal pore size is for storage and whether the designed pore size lies above or below this value. If the pore size is too low for significant uptake, further decreases in pore size do not lead to achievement of the objective of obtaining a reasonable storage capacity while increasing the rate of dissipation of heat. In addition to pore size, pore shape also effects thermal conductivity. MOFs with hexagonal channels have the highest thermal conductivities along the channel direction and lowest thermal conductivities across the channel direction. Furthermore, the interpenetration of MOFs leads to parallel thermal transport pathways as shown by molecular dynamics simulations. This leads to a thermal conductivity that is the sum of the thermal conductivities of the two constituent frameworks [72]. This would allow for more rapid transport of heat. This phenomenon holds for both cubic idealized MOFs and IRMOF-1. In cases where the frameworks are not maximally interpenetrating and the interframework attraction is high, which is not very common, the thermal conductivity might be lower than that of the sum of the individual frameworks due to the effect of coupling. The coupling factor that is calculated using the force field parameters $(\sigma$ and $\varepsilon$ ) from molecular dynamics can be used to determine the decrease in thermal conductivity and was minimal for $0.01<\varepsilon<0.1 \mathrm{kcal} \mathrm{mol}^{-1}$ and $1<\sigma<4.5 \AA$. These molecular dynamics simulations suggest a new strategy for the addition of frameworks to form an interpenetrated MOF structure with a larger number of adsorption sites and additional thermal transport pathways for thermal management. However, there may be a drawback to this strategy if the pore volume is too low for gas storage. The gas in the pores affects the thermal conductivity of the system. It was found that the thermal conductance of the MOF adsorption system is dominated by the lattice thermal conductivity and that conductance is reduced as the concentration of gas in the pores increases by transient simulations [65]. The thermal transport is two orders of magnitude faster than gas diffusion. The fast release of heat is hindered by a large thermal resistance at the gas-MOF interface (Figure 2). The gas-MOF interface does not bottleneck the adsorption process. The thermal conductivities of some MOFs were measured. UiO-66, UiO-67 and Cu-BTC have thermal conductivities of $0.11 \mathrm{~W}(\mathrm{~m} \cdot \mathrm{K})^{-1}, 0.19 \mathrm{~W}(\mathrm{~m} \cdot \mathrm{K})^{-1}$, and $0.39 \mathrm{~W}(\mathrm{~m} \cdot \mathrm{K})^{-1}$, respectively [73]. The thermal conductivity of MOF-5 was measured to be $0.32 \mathrm{~W}(\mathrm{~m} \cdot \mathrm{K})^{-1}$ [74]. More thermal conductivity data of MOFs is needed. 


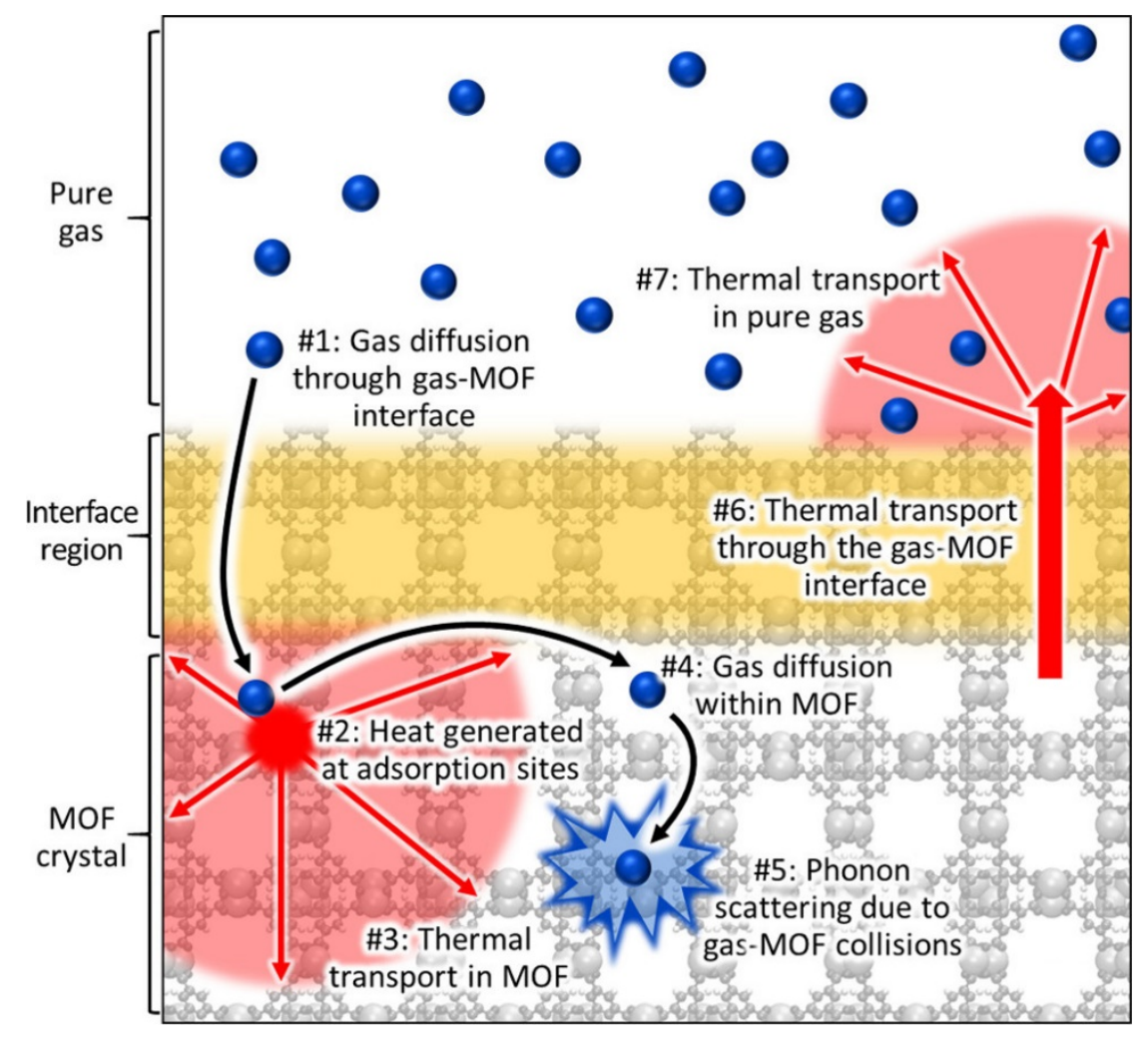

Figure 2. Thermal and mass transport during gas adsorption in a MOF. Reprinted with permission from Ref. [65]. Copyright 2018 American Chemical Society.

Another factor to consider in thermal management is that some MOFs strongly interact with natural gas and methane. As a result, there is a heat release associated with the isosteric heat of adsorption (Qst). During operation of ANG systems, heat may raise the system's temperature and decrease deliverable capacity. In Table 1, the isosteric heat of adsorption of selected MOFs is provided. $\mathrm{Q}_{\text {st }}$ ranges from around 5 to $25 \mathrm{~kJ} \mathrm{~mol}^{-1}$. Therefore, thermal management may consider the heat of adsorption of the material to design MOFs for ANG systems. Lower heats of adsorption may decrease the temperature swing during the charging and discharging of the tank. The heat of adsorption can be optimized during the design and selection of the MOF to minimize temperature swings and maximize gas storage and delivery [75].

Managing the thermal fluctuations associated with adsorption and desorption presents challenges while maintaining the high capacities required of the system [76]. Another strategy to address this problem is to select materials that undergo phase transitions to absorb and release heat during adsorption and desorption. For example, the phase transitions of Fe(bdp) (bdp =1,4-benzenedipyrazolate) and $\mathrm{Co}(\mathrm{bdp})$ in response to changes in pressures result in a sharp 'step' in the adsorption and desorption isotherms. The phase transition energy can be tuned and was used to manage the temperature change associated with adsorption and desorption.

Adsorption isotherms typically exhibit Langmuir-type isotherms and possess a decreasing rate of the amount of $\mathrm{CH}_{4}$ adsorbed as the pressure is increased (Figure 3). To overcome this, a material possessing a stepped isotherm was used whereby the adsorbed amount is low at about 5 bar and high at 65 bar. A phase exists that has a collapsed structure in addition to an expanded phase which can adsorb more methane. The phase transition is reversible and occurs over 100 adsorption cycles. X-ray diffraction (XRD) was used to discover that the phase transition occurs around 17 to 23 bar for $\mathrm{Fe}(\mathrm{bdp})$ and $\mathrm{Co}(\mathrm{bdp})$. The density of the expanded phase $\left(0.77 \mathrm{~g} \mathrm{~cm}^{-3}\right)$ is nearly half of that of the collapsed phase $\left(1.50 \mathrm{~g} \mathrm{~cm}^{-3}\right)$. On the other hand, HKUST-1 and UTSA-76a $\left(\left[\mathrm{Cu}_{2} \mathrm{~L}\left(\mathrm{H}_{2} \mathrm{O}\right)_{2}\right]^{*} 5 \mathrm{DMF}^{*} 3 \mathrm{H}_{2} \mathrm{O}\right)$ possess Langmuir-type adsorption isotherms and therefore a significant amount of $\mathrm{CH}_{4}$ is left adsorbed at 
lower pressures of around 5 bar. By changing the material used from $\mathrm{Co}(\mathrm{bdp})$ to $\mathrm{Fe}(\mathrm{bdp})$ there is a $12 \%$ lower heat released per liter of adsorbent and $\mathrm{Fe}(\mathrm{bdp})$ released $41 \%$ less heat per liter of adsorbent than HKUST-1.

The MIL-53 family ( $\mathrm{M}=\mathrm{Al}, \mathrm{Fe}, \mathrm{Ga}$, In) of benzene-1,4-dicarboxylates are MOFs with breathing properties which can be easily synthesized and have high stability [77-79]. These breathing properties are based on a phase transition that can be used in thermal management. The pores of MIL-53 can change from a narrow phase (np) to a large phase (lp) based on the temperature, pressure and adsorbent type. When adsorbing methane, MIL-53(Al) exhibits breathing properties at low temperatures and pressure due to the low stability of the (np) phase. At room temperature, the breathing properties are due to hydrogen bonding that leads to the greater stability of a very narrow pore phase (vnp) and the (np) phase of framework $[77,78]$. The adsorption of MIL-53(Al)- $\mathrm{NH}_{2}$ for methane is performed under a certain pressure and temperature, which leads to liquefaction. The MIL-53 [78] delivered capacity is low, because (lp) phase of MIL-53(Al) is stable. Provoking the (lp) phase is important for a good performance of MIL-53(Al)- $\mathrm{NH}_{2}$, although high pressure is needed to have a complete (lp) phase transition. The limitation in performance can be overcome by provoking an (np) to (lp) phase transition at lower pressure [80]. To reach this transition, we must increase the stability of the (lp) phase over the (np) phase and the (vnp) and (np) stability depend on the hydrogen bonding between the amino group of the ligand and oxygen atoms of the metal. Furthermore, the MIL-53(Al)- $\mathrm{NH}_{2}$ delivered capacity can be enhanced by investigating heat of adsorption and a memory effect of the framework. The exothermic adsorption generates energy for the phase change in MOFs and desorption is endothermic, which cools the system if it is stopped at high pressure. When a second adsorption is performed, the energy generated in the system leads to the (np) - (lp) transition that results in a higher uptake. In the case of methane adsorption or desorption of MIL-53(Al)- $\mathrm{NH}_{2}$ between 45 and 65 bar, it is possible to increase methane uptake without the need of a higher pressure. 
Table 1. Pore volume, uptake and deliverable capacity of selected MOFs.

\begin{tabular}{|c|c|c|c|c|c|c|c|c|c|c|c|c|}
\hline MOF & $V_{P}\left(\mathrm{~cm}^{3} \mathrm{~g}^{-1}\right)^{a}$ & $\begin{array}{l}\text { BET } \\
\left(\mathrm{m}^{2} \mathrm{~g}^{-1}\right)\end{array}$ & $\begin{array}{l}\text { Uptake }{ }^{b} \\
\left(\mathrm{~cm}^{3} \mathrm{~cm}^{-3)}\right.\end{array}$ & $\begin{array}{l}\text { Delivery } \\
\left(\mathrm{cm}^{3} \mathrm{~cm}^{-3}\right)\end{array}$ & $\begin{array}{l}T \\
(K)\end{array}$ & $\begin{array}{l}\mathbf{P} \\
\text { (bar) }\end{array}$ & $\begin{array}{l}\text { Uptake }^{\mathrm{b}} \\
\left(\mathrm{cm}^{3} \mathrm{~cm}^{-3}\right)\end{array}$ & $\begin{array}{l}\text { Delivery } \\
\left(\mathrm{cm}^{3} \mathrm{~cm}^{-3}\right)\end{array}$ & $\begin{array}{l}T \\
(K)\end{array}$ & $\begin{array}{l}\mathbf{P} \\
\text { (bar) }\end{array}$ & $\begin{array}{l}\mathrm{Q}_{\mathrm{ST}} \\
\mathrm{kJ} \mathrm{mol}^{-1}\end{array}$ & REF \\
\hline PCN-61 & 1.36 & 3000 & 171 & 127 & 298 & 35 & 219 & 174 & 298 & 65 & - & [45] \\
\hline HKUST-1 & 0.71 & 1555 & 190 & - & 303 & 35 & 254 & - & 303 & 65 & 20.7 & [48] \\
\hline MgMOF-74 & 0.69 & - & 200 & 113 & 298 & 35 & 230 & 142 & 298 & 65 & 18.5 & [60] \\
\hline MOF-5 & 1.4 & - & 150 & 118 & 298 & 35 & 214 & 182 & 298 & 65 & 12.3 & [60] \\
\hline Cu-TDPAT & 0.93 & 1938 & 181 & 122 & 298 & 35 & 222 & 163 & 298 & 65 & - & [43] \\
\hline PCN-14 & 0.83 & 1984 & 202 & 125 & 298 & 35 & 239 & 160 & 298 & 65 & 17.6 & [60] \\
\hline CoMOF-74 & 0.51 & - & 221 & 110 & 298 & 35 & 249 & 136 & 298 & 65 & 19.5 & [60] \\
\hline PCN-61 & 1.36 & 3000 & 171 & 127 & 298 & 35 & 219 & 174 & 298 & 65 & - & [81] \\
\hline MOF-210 & 3.60 & 6240 & 83 & 71 & 298 & 35 & 143 & 131 & 298 & 65 & - & [45] \\
\hline PCN-14 & 0.85 & 2000 & 195 & 122 & 298 & 35 & 230 & 157 & 298 & 65 & 18.7 & [82] \\
\hline NU-111 & 2.09 & 4930 & 138 & 111 & 298 & 35 & 206 & 179 & 298 & 65 & 14.2 & [82] \\
\hline NU-140 & 1.97 & 4300 & 138 & 108 & 298 & 35 & 200 & 170 & 298 & 65 & 14 & [51] \\
\hline NU-125 & 1.29 & 3120 & 181 & 133 & 298 & 35 & 228 & 180 & 298 & 58 & 15.5 & [83] \\
\hline NiMOF-74 & 0.47 & 1218 & 214 & 94 & 298 & 35 & 236 & 116 & 298 & 65 & - & [77] \\
\hline NU-111 & 2.09 & 4930 & 138 & 111 & 298 & 35 & 206 & 179 & 298 & 65 & 15.2 & [84] \\
\hline NOTT-109 & 0.850 & 2110 & 196 & 125 & 300 & 35 & 242 & 170 & 300 & 65 & 17.1 & [85] \\
\hline ZJU-5 & 1.074 & 2823 & 190 & 130 & 300 & 35 & 228 & 168 & 300 & 65 & 15.3 & [66] \\
\hline ZJU-25 & 1.183 & 2124 & 180 & 132 & 300 & 35 & 229 & 181 & 300 & 63 & 15.1 & [86] \\
\hline NU-135 & 1.02 & 2530 & 187 & 127 & 298 & 35 & 230 & 170 & 298 & 65 & 16.6 & [87] \\
\hline NOTT-100 & 0.677 & 1661 & 195 & 104 & 300 & 35 & 230 & 139 & 300 & 65 & 18.1 & [85] \\
\hline
\end{tabular}



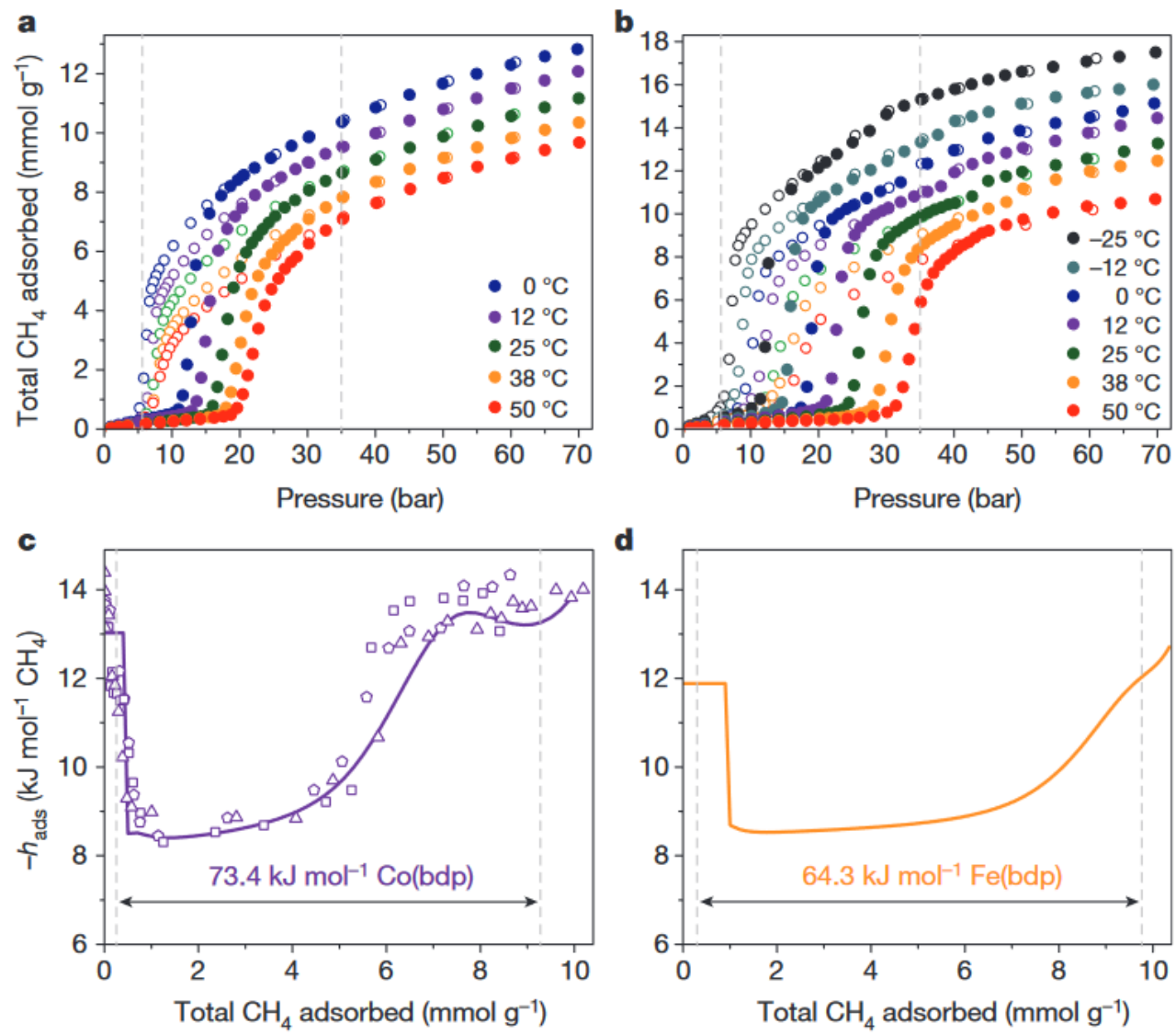

Figure 3. Variable-temperature equilibrium isotherms and differential enthalpies. A,b, Total $\mathrm{CH}_{4}$ adsorption isotherms at various temperatures for $\mathrm{Co}(\mathrm{bdp})(\mathbf{a})$ and $\mathrm{Fe}(\mathrm{bdp})(\mathbf{b})$, where a minimum desorption pressure of 5.8 bar and a maximum adsorption pressure of 35 bar are indicated by dashed grey lines. Filled circles represent adsorption; open circles represent desorption. (c) Differential enthalpies of $\mathrm{CH}_{4}$ adsorption (hads) for $\mathrm{Co}(\mathrm{bdp})$ as determined from variable-temperature adsorption isotherms (purple line) and three separate microcalorimetry experiments (open symbols). (d) Differential enthalpies of $\mathrm{CH}_{4}$ adsorption (hads) for $\mathrm{Fe}(\mathrm{bdp})$, as determined by variable-temperature adsorption isotherms. Dashed grew lines in c and d indicate the amount of $\mathrm{CH}_{4}$ adsorbed at 5.8 bar and 35 bar. Reprinted with permission from Ref. [76]. Copyright 2015 Springer Nature.

\section{Mechanical Properties}

The volume of gas/volume of container $(\mathrm{V} / \mathrm{V})$ values based on powder adsorption that do not account for losses due to pelletization and bed porosity overestimate the working storage capacity. Furthermore, interparticle void space results in a lower volumetric $\mathrm{CH}_{4}$ capacity. For onboard applications, the material is extruded or pelletized to reduce the pressure drop. This results in a loss of pore volume and/or surface area [88]. Compaction can also result in complete or partial collapse of the framework pores. Pellets of $\mathrm{Ni}_{2}$ (dobdc) (dobdc ${ }^{4-}=2,5$-dioxido-1,4-benzenedicarboxylate) compacted with $0.1 \mathrm{GPa}$ of pressure adsorbed just $100 \mathrm{v} / \mathrm{v}$ of $\mathrm{CH}_{4}$ at 34 bar and $30^{\circ} \mathrm{C}$ as compared to $230 \mathrm{v} / \mathrm{v}$ before compaction $[60,89]$. To meet the Department of Energy target of $263 \mathrm{~V} / \mathrm{V}$ at the onboard packed bed level, the volumetric loadings for the pelletized sample should be about $373 \mathrm{~V} / \mathrm{V}$ [66]. Therefore, MOFs with high mechanical stability are desirable for implementation in ANG systems. These materials can survive compaction without losing their porosity and storage capacity.

To tackle this issue, advanced synthesis engineering and densification of MOFs was used to produce monolithic structures of up to about $1 \mathrm{~cm}^{3}$ in size without high pressure and binders [90]. HKUST-1 was synthesized by a sol-gel process and analyzed by optical imaging of the sample as well as powder XRD. The unreacted particles nucleate at the interface connecting the existing primary 
particles together and results in an epitaxial growth, yielding a dense monolith. After successful packing and densification, the monolithic HKUST-1 achieved a capacity of $259 \mathrm{~cm}^{3}(\mathrm{STP}) \mathrm{cm}^{-3}$, which is a $50 \%$ improvement over any other experimental value and virtually matches the DOE target of $263 \mathrm{~cm}^{3}$ (STP) $\mathrm{cm}^{-3}$ (Figure 4). The hardness of the monolithic HKUST-1 is at least $130 \%$ greater than that value measured for other conventional MOFs.

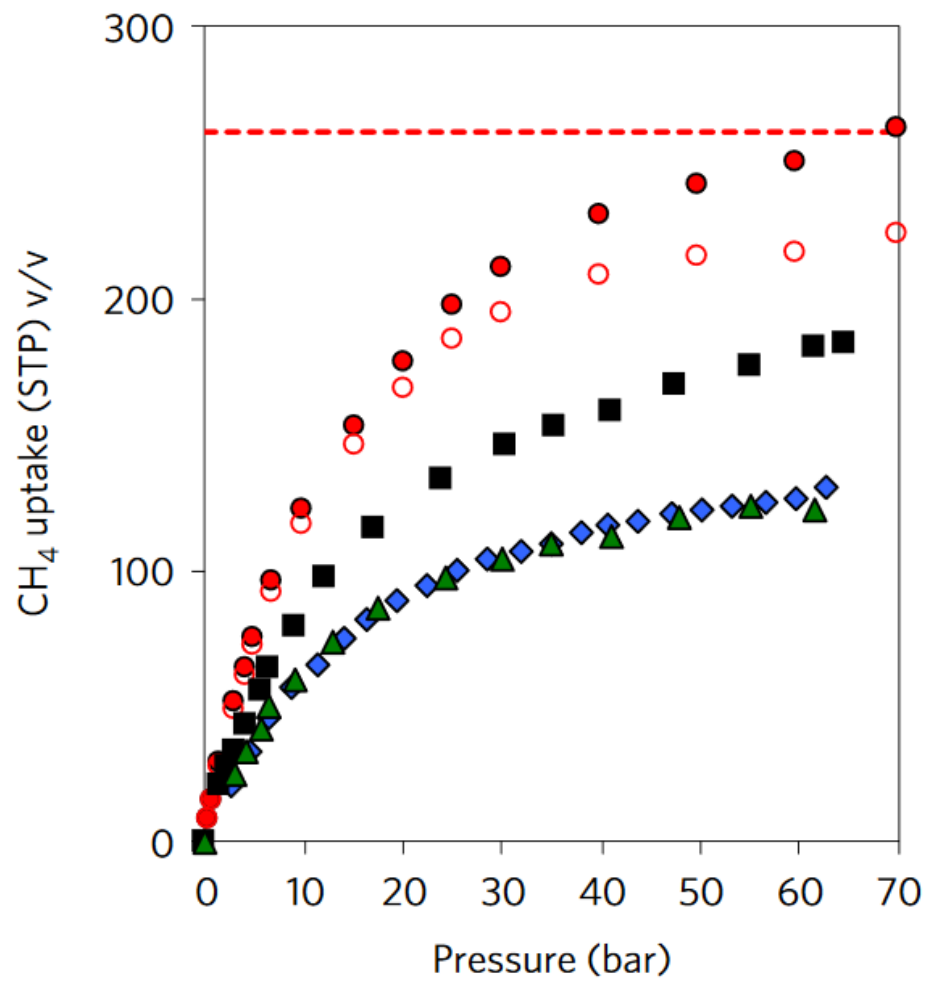

Figure 4. Gas adsorption in HKUST-1. Comparison of absolute volumetric methane adsorption isotherms at $298 \mathrm{~K}$ on monolithic HKUST-1 (red filled circles), excess volumetric uptake on monolithic HKUST-1 (red open circles), HKUST-1 pellets under hand packing (blue diamonds), HKUST-1 pellets packed under 27.6 MPa (black squares), and HKUST-1 pellets under 68.9 MPa (green triangles) 5. The DOE target of $263 \mathrm{~cm}^{3}$ (STP) $\mathrm{cm}^{-3}$ is represented by the red dashed line. Adapted with permission from Ref. [90]. Copyright 2017 Springer Nature.

The intrinsic mechanical properties of each material cannot be compared based on compaction studies because particle size and shape and mechanical stability affect the outcomes of these studies. Textural characterization indicates a significant effect of compression on the microcrystallinity of HKUST-1 as shown by XRD analysis [91]. The loss of crystallinity is proportional to the applied force. Computationally, the mechanical stability can be assessed by the pressure-versus-volume equations of state [92]. Another thing to note is that defects in MOFs may compromise mechanical stability although they may add adsorption capability [93]. In the case of UiO-66, the onset of amorphization and decreasing bulk modulus occurs at around $0.2 \mathrm{GPa}$ as a function of defect concentration [94]. Furthermore, MOF mechanical structure-property relationships due to defects and interpenetration were discussed [95]. The addition of mesoporosity into MOFs seems to leave sufficient mechanical stability as seen in the case of HKUST-1 [96].

The mechanical behavior of MOFs can be tuned by functionalization [97]. UiO-66( $\mathrm{Zr})$ and MIL-125(Ti) and their amino-functionalized derivatives showed a gradual pressure-induced reversible decrease in their crystallinity as determined by high-pressure powder X-ray diffraction up to $3.5 \mathrm{GPa}$. $\mathrm{UiO}-66(\mathrm{Zr})$ has a very high bulk modulus and found to be one of the most resilient MOFs studied. The mechanical behavior of MOFs was correlated to chemical and geometrical features such as metal-oxygen coordination number, the nature of the organic linker, and the porosity and crystal 
density. In another study, a rationalization was provided relating the mechanical properties of MOFs to framework bonding topology and ligand structure [98]. Functional groups on the organic ligands that comprise the MOF structure can enhance mechanical stability through the formation of a secondary network of nonbonded interactions or can soften the material by destabilizing the bonded network of a MOF. Therefore, mechanical stability may be improved by the selection of functional groups.

\section{Natural Gas Impurities}

Another factor to consider in the implementation of the system is the effect of impurities such as higher hydrocarbons. Natural gas consists of about 90\% methane, 3\% ethane, 1\% C3-C6 hydrocarbons, and 3\% nitrogen [99]. It is not practical to separate all the components other than methane before charging a tank [100]. These hydrocarbons and impurities can have a deleterious effect and decrease methane storage capacity and affect the long-term stability of the adsorbent. C2 and C3 hydrocarbons may block the binding sites, decreasing deliverable capacity. Furthermore, the interaction of adsorbent and adsorbate results in heat being adsorbed or desorbed during the operation of ANG systems.

According to a computational study, the adsorbed natural gas tank performance declines and deliverable energy decreases over 200 operating cycles [101]. A 'cyclic steady state' is reached following a monotonic decline. The best MOFs tested at 'cyclic steady state' ordering in increasing performance are MOF-143 > NU-800 > IRMOF-14 > IRMOF-20 > MIL-100 > NU-125 > IRMOF-1 > NU-111. The highest cyclic steady state energy delivered is $5.43 \mathrm{MJ} \mathrm{L}^{-1}$. HKUST-1 and IRMOF-1 have the best deliverable capacity of $\sim 185 \mathrm{~cm}^{3}$ (STP) $\mathrm{cm}^{-3}$ of adsorbent at pressures between 5.8 and 65 bar. A small amount of higher hydrocarbons can have a significant effect and reduces the deliverable energy to $5.08 \mathrm{MJ} \mathrm{L}^{-1}$. When comparing NU-125 and HKUST-1, one can see that the deliverable energy content of HKUST-1 decreases sharply to $3.96 \mathrm{MJ} \mathrm{L}^{-1}$ due to the presence of the higher hydrocarbons (Figure 5). HKUST-1 has three cavities, with the smaller one having a diameter of $5.5 \AA$. The small pore diameter is detrimental to the performance of this MOF and was outperformed by NU-125. NU-800 was predicted to perform best under operating conditions. In this study, it was found that the initial deliverable capacity correlates well with methane storage capacity. Furthermore, the cumulative deliverable energy correlated with the deliverable energy at the 200th cycle. At higher temperatures, the adsorption capacities of MOFs are reduced [72].

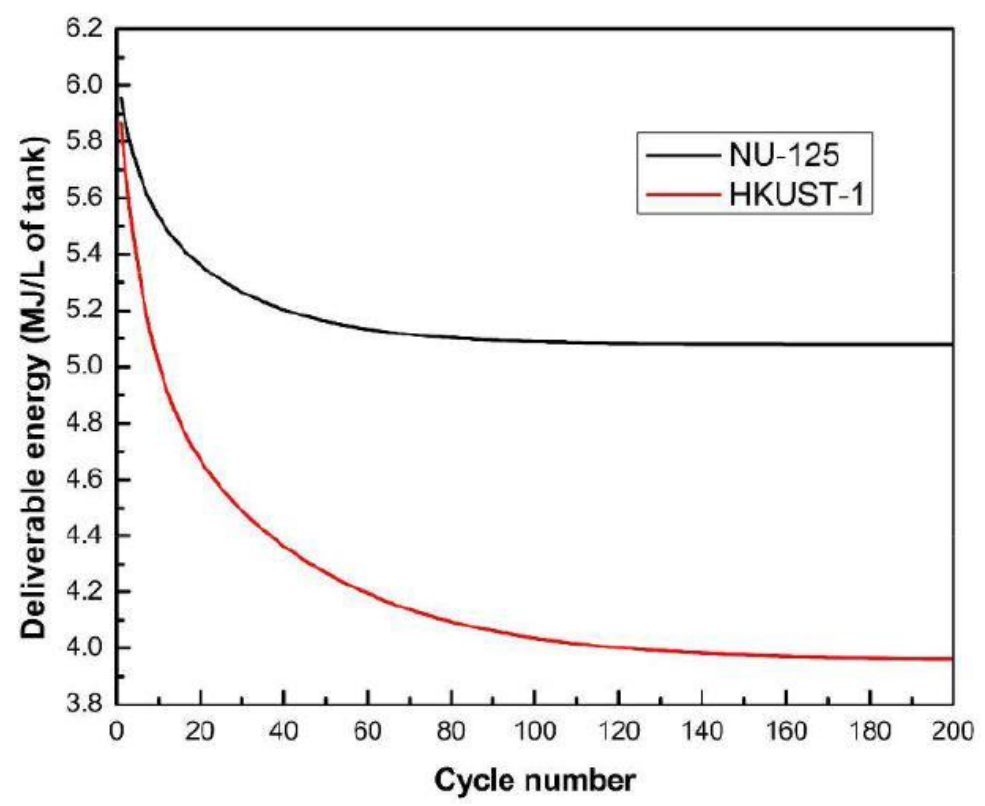

Figure 5. Deliverable energy of each cycle in NU-125 and HKUST-1 between 5.8 and 65 bar. Reprinted with permission from Ref. [101]. Copyright 2015 Royal Society of Chemistry. 
In another computational study, the impacts of gas impurities from pipeline natural gas on methane storage in MOFs during long-term cycling was studied [102]. Grande Canonical Monte Carlo (GCMC = Grande Canonical Monte Carlo) and ideal adsorption solution theory (IAST = ideal adsorption solution theory) of multicomponent adsorption were used to study an isothermal tank to assess the accumulation of heavy hydrocarbons and tert-butyl mercaptan (TBM). The deliverable energy was found to reduced up to $50 \%$ after 200 cycles. This result again highlights the importance of multicomponent effects on ANG systems.

The pores in MOFs can be tuned as seen for NJU-Bai. This is associated with the sub cage elimination and pore polarization (Figure 6). Cages can be eliminated and the pores polarized by linker slimming, polarization, and expansion. NJU-Bai42 exhibits a higher volumetric methane working capacity than HKUST-1 of $193 \mathrm{~cm}^{3}$ (STP) $\mathrm{cm}^{-3}$ [103]. NJU-Bai43 possesses the highest volumetric storage capacity of $254 \mathrm{~cm}^{3}$ (STP) $\mathrm{cm}^{-3}$. This corresponds to four times increase of deliverable working capacity as compared to a tank filled with methane [103]. The adsorption enthalpies of NJU-Bai 41, NJU-Bai 42, and NJU-Bai 43 were calculated to be $17.77,14.49$, and $14.45 \mathrm{~kJ} \mathrm{~mol}^{-1}$.
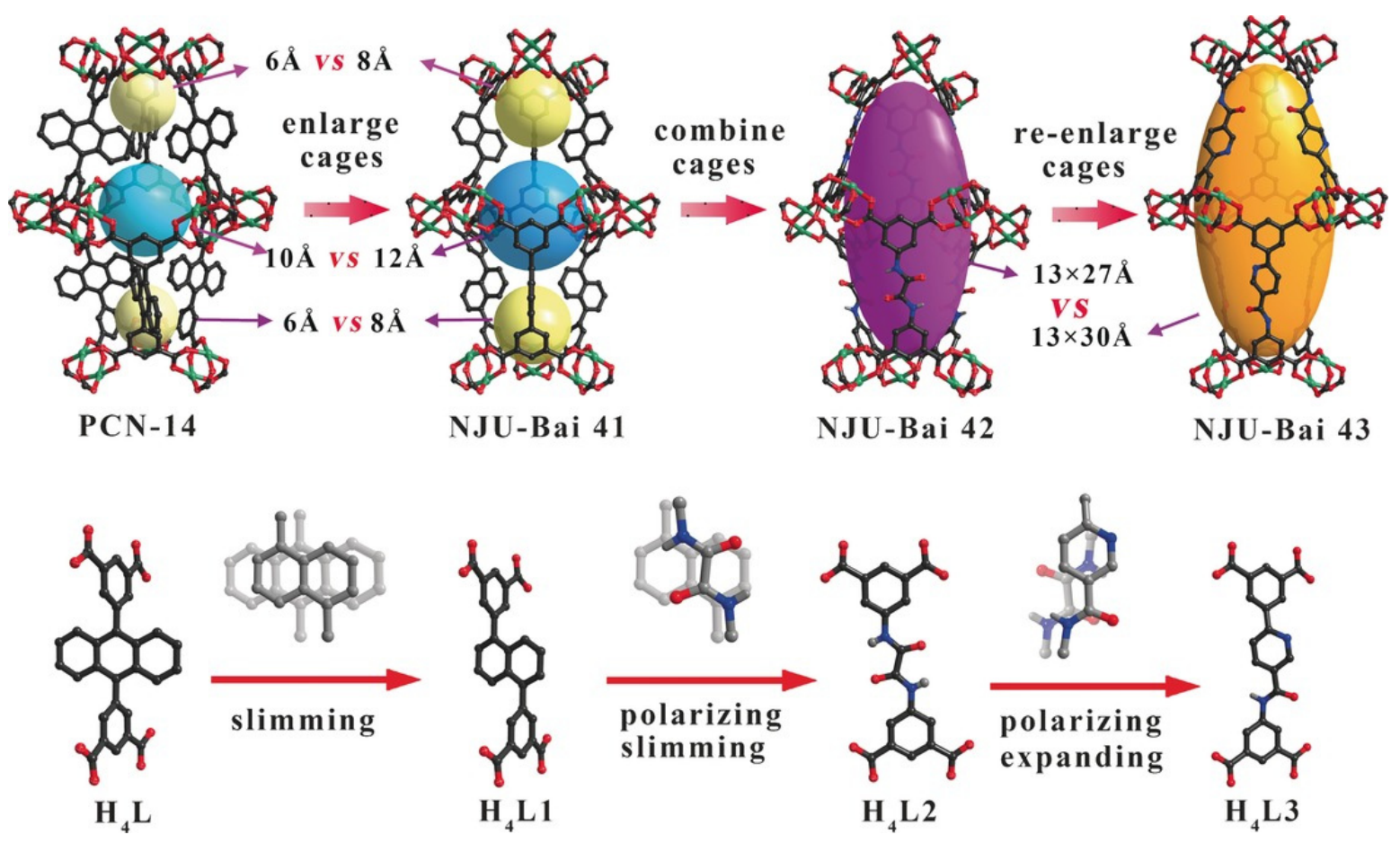

Figure 6. The development from PCN-14 to NJU-Bai 43. The organic linkers, cage size, pore surface properties, and the gravimetric surface area are optimized in a systematic manner. Reprinted with permission from Ref. [103]. Copyright 2017 John Wiley and Sons.

Regeneration is one option to regain performance after cycling in microporous materials [104]. In the case of a commercial, high-surface-area activated carbon (Maxsorb MSC-30, Kansai Coke and Chemical Co. Ltd.), a similar phenomenon as seen in MOFs was found with a $50 \%$ deterioration of volumetric storage capacity after 100 cycles. It was found that the composition of the gas retained in the pores was mostly C3-C5 hydrocarbons. The performance, based on the gravimetric excess adsorption capacity, can be improved after the $50 \%$ deterioration by regeneration at $400{ }^{\circ} \mathrm{C}$ and $2 \mathrm{~h}$ under vacuum (up to $10^{-4}$ torr). In the case of MOFs, lower temperatures may be required based on the stability of the MOFs. Combined with regeneration, a reasonable performance may be obtained for 1000 cycles.

Future work should seek to address information needed in this area of research. An important experiment that is missing from published experiments on the application of MOFs for ANG is the evolution of storage capacity during the adsorption/desorption cycles using a natural gas feed. Although there are computation studies on this, no experimental results have yet been reported for 
MOFs. In addition, the evolution of the gas composition during the adsorption/desorption cycles measured by experiments would be something that would be useful to know. This would provide insights into the behavior of the system. Another thing to consider is the effect of natural gas composition on storage capacity. Finally, the development of regeneration techniques for the storage of natural gas by MOFs is of importance for practical implementation. These experiments would provide information regarding what technological advancements are still needed in this area of research. Future studies are not only expected to build on these developments, but also provide a deeper understanding of how MOF structures can be tuned to affect the adsorption isotherm and subsequently the working capacity. This will provide further design strategies for the optimization of the properties of MOFs for this application.

\section{Practical Implementation}

BASF, a German chemical company and the largest chemical company producer in the world, fitted fuel tanks packed with BASF MOFs for natural gas storage in transportation application in the EcoFuel World Tour in 2007 [105]. BASF enhanced the natural gas storage capability by taking advantage of the favorable properties of MOFs, such as their surface areas coupled and their favorable energetics for adsorbing gas. Cylinders filled with MOFs store twice as much gas as do standard cylinders. The test successfully resulted in a six-month, 28,000-mile road trip fueled by natural gas through 40 countries and five continents in a Volkswagen Caddy optimized for natural gas combustion [106]. The road trip was aimed at increasing public awareness of the environmental benefits of using natural gas instead of conventional transportation fuels. The MOF-enhanced system provided an overall driving range of more than 1,500 miles between fill-ups. In 2013, BASF followed up with a showcase. A heavy-duty Kenworth truck was equipped with natural gas fuel systems containing BASF MOF materials. In partnership with Quantum Technologies, a storage system was designed that utilized a type IV natural gas storage pressure vessel marking the advancement of MOF technology [107].

In 2017, BASF continued its MOF commercialization efforts with a focus on higher valued areas, like specialty chemicals [108]. BASF produced 100 different types of MOFs at the lab scale. The company is selling MOFs via Merck KGaA subsidiary Sigma-Aldrich. HKUST-1, a benchmark MOF for methane storage, is being sold as Basolite C 300. $500 \mathrm{~g}$ of Basolite $\mathrm{C} 300$ was sold by Merck for $\$ 9,200$. Companies like NUMAT, novoMOF, MOFonics, MOF Technologies, Green Science Alliance Co., Ltd. and BASF have been scaling-up MOF production [109]. NuMAT brought the first MOF-enabled gas storage product to market in partnership with Linde Group, the second-largest gas company in the world in 2017 [110]. NuMat is now producing hundreds of $\mathrm{kg}$ of MOFs in a few hours. NuMat and MOF Technologies have made major strides, but BASF is still a major player for MOF production.

For practical implementation, the cost of MOF manufacture should be considered and minimized [111]. A techno-economic analysis was conducted for metal-organic framework (MOF) adsorbents for large-scale manufacture [112]. $\mathrm{Ni}_{2}$ (dobdc) (dobdc4- = 2,5-dioxido-1,4-benzenedicarboxylate; Ni-MOF-74), $\mathrm{Mg}_{2}$ (dobdc) (Mg-MOF-74), $\mathrm{Zn}_{4} \mathrm{O}(\mathrm{bdc})_{3}\left(\mathrm{bdc}^{2-}=1,4\right.$-benzenedicarboxylate; MOF-5), and $\mathrm{Cu}_{3}(\mathrm{btc})_{2}$ (btc ${ }^{3-}$ $=1,3,5$-benzenetricarboxylate; HKUST-1) have projected costs in the range of $\$ 35 \mathrm{~kg}^{-1}$ to $\$ 71 \mathrm{~kg}^{-1}$ based on organic solvent for solvothermal syntheses. Alternative synthesis methods such as liquid assisted grinding (LAG) and aqueous synthesis reduce cost by reducing solvent usage and provide cost projections in the range from $\$ 13 \mathrm{~kg}^{-1}$ to $\$ 36 \mathrm{~kg}^{-1}$ (representing 34-83\% reductions) for scaled-up manufacture [113]. Scalable, continuous processes for manufacture have also been investigated [114-117]. The NU-125 MOF can be made in high yield on the gram-scale [83]. This porous material has a low capacity in the 5-8 bar range as it is best for the material to have high capacity in the 60-70 bar range. Hence, NU-125 benefits from a careful balance of strong binding sites and weakly binding surfaces. Finally, in order to test sample stability, the methane isotherm measurements were repeated (cycled) in succession over a period. In addition, high pressure $\mathrm{CH}_{4}$ adsorption was measured over a wide range of temperatures on the same sample. The absence of sample degradation over time from cycling indicates that NU-125 is robust. This demonstrates that MOFs may be made on a large scale with high working capacity. 
The synthesis of MOFs on an industrial scale must be considered for practical implementation and for the design of MOFs [118]. The production of gram-scale quantities of MOF has been considered as well as technoeconomic analysis of MOF production. These studies point to synthesis strategies that help in the design of MOFs. These included minimizing cost in organic linker selections and minimizing solvent exchange steps. These approaches lead to more than $30 \%$ reduction of cost required for practical implementation. The research described here represents the main strategies for the design of MOFs for natural gas storage and delivery that have been applied in MOF chemistry to date.

\section{Conclusions and Outlook}

Significant advances were made with respect to the design of MOFs for natural gas and methane storage and delivery with the 2012 DOE target being nearly met in 2018. These advances are expected to be critical for on-board vehicle applications where a high level of performance in several areas are required of these materials with respect thermal properties, mechanical properties, and effect of natural gas impurities on the working capacity. The complexity of the real-world application of such a system has provided additional problems required to be considered for seamless practical application. Significant design challenges remain in the area and new experimental work is needed. With computational work predicting the effect of natural gas impurities, it is critical for experimental work to continue because of its paramount importance in identifying limitations for real-world applications. Fundamental understanding missed by some computational studies for real-world applications is needed, such as identifying extra-adsorption sites, phase change processes, MOF structural phase changes, and structure flexibility [119] during adsorption, which have been partially explored experimentally.

Thermal management associated with mitigating temperature swings during adsorption and desorption which decrease deliverable capacity can also be addressed in the design through the incorporation of MOF phase transitions whose temperatures and pressures can be tuned in the design stage. This leads to thermodynamically rich phenomena, which not only affect natural gas storage and delivery but also hydrocarbon separation, hydrogen storage, and medicinal applications of MOFs. The mechanical properties of MOFs are important to consider or practical application because MOFs are typically packed before they can be implemented in natural gas storage systems. Compaction of certain elegant MOF structures can result in complete or partial collapse of the framework pores, decreasing their deliverable capacities. In the case of the effect of impurities on such systems, a poisoning effect has been found. This decreases the performance of such systems after many cycles, which results in a decrease in the deliverable capacity of natural gas by up to $50 \%$. This challenge can be addressed during the design stage of MOFs as has been demonstrated through the careful design of the pore structure of the MOF. Additional research can be done for the design of guard columns for these systems.

To accommodate the real-world applications of MOFs for ANG, the characteristics that need to be achieved by MOFs to replace currently established and widespread technology are increased working capacity for greater driving ranges, favorable heat transfer properties, light-weight material, excellent cyclability, and resistance to impurities. In addition, it is critical to minimize the cost of MOFs for commercial viability. The contributions of researchers from chemistry, physics, and thermodynamics are expected to accelerate research in this area and lead to innovative design strategies and new findings. These new materials and the application of discovered MOFs to this area are likely to provide a new interface between MOF chemistry and other areas of science and technology.

Author Contributions: Conceptualization, E.M.; formal analysis, E.M.; investigation, E.M.; resources, E.M.; writing-original draft preparation, E.M., L.A., A.E.S., S.A.A., H.A., M.J., and A.H.A.; writing-review and editing, E.M.; visualization, E.M.; supervision, E.M.; project administration, E.M.; funding acquisition, E.M.

Funding: This research was funded by United Arab Emirates University, grant no G00002618.

Conflicts of Interest: The authors declare no conflict of interest. 


\section{References}

1. BP Energy Outlook 2017 Edition. Available online: https://safety4sea.com/wp-content/uploads/2017/01/BPEnergy-Outlook-2017_01.pdf (accessed on 4 August 2019).

2. Schoedel, A.; Ji, Z.; Yaghi, O.M. The role of metal-organic frameworks in a carbon-neutral energy cycle. Nat. Energy 2016, 1, 1-13. [CrossRef]

3. The Outlook for Energy: A View to 2040. Available online: https://cdn.exxonmobil.com/ \{\}/media/global/ files/outlook-for-energy/2016/2016-outlook-for-energy.pdf (accessed on 4 August 2019).

4. IEA. Key World Energy Statistics. Available online: https://www.connaissancedesenergies.org/sites/default/ files/pdf-actualites/keyworld_statistics_2015.pdf (accessed on 25 June, 2018).

5. BP Statistical Review of World Energy June 2015. Available online: https://www.bp.com/content/dam/bpcountry/es_es/spain/documents/downloads/PDF/bp-statistical-review-of-world-energy-2015-full-report. pdf (accessed on 4 August 2019).

6. CO2 Emissions (kt) | Data. Available online: https://data.worldbank.org/indicator/EN.ATM.CO2E.KT (accessed on 2 July 2018).

7. Zhou, N.; Fridley, D.; McNeil, M.; Zheng, N.; Ke, J.; Levine, M. China's Energy and Carbon Emissions Outlook to 2050. Ernest Orlando Lawrence Berkeley Natl. Lab. 2011, 1-66.

8. 2030 Climate \& Energy Framework | Climate Action. Available online: https://ec.europa.eu/clima/policies/ strategies/2030_en (accessed on 31 July 2019).

9. Coren, M.J. Nine Countries Say They'll Ban Internal Combustion Engines. Available online: https://qz.com/1341155/nine-countries-say-they-will-ban-internal-combustion-engines-none-have-alaw-to-do-so/ (accessed on 31 July 2019).

10. Painuly, J.P. Barriers to renewable energy penetration: A framework for analysis. Renew. Energy 2001, 24, 73-89. [CrossRef]

11. Akella, A.K.; Saini, R.P.; Sharma, M.P. Social, economical and environmental impacts of renewable energy systems. Renew. Energy 2009, 34, 390-396. [CrossRef]

12. Drennen, T.E. Renewable Energy: Sources for Fuels and Electricity. J. Environ. Qual. 1994, 23, 622. [CrossRef]

13. ARPA-E MOVE Program Overview. Available online: http://arpa-e.energy.gov/sites/default/files/documents/ files/MOVE_ProgramOverview.pdf (accessed on 4 August 2019).

14. Current Natural Gas Vehicle Statistics | NGV Global Knowledgebase. Available online: http://www.iangv. org/current-ngv-stats/ (accessed on 31 July 2019).

15. Bae, C.; Kim, J. Alternative fuels for internal combustion engines. Proc. Combust. Inst. 2017, 36, 3389-3413. [CrossRef]

16. Compressed Natural Gas (CNG) in transport | ClimateTechWiki. Available online: https://www. climatetechwiki.org/technology/cng (accessed on 31 July 2019).

17. Dobrota, Đ.; Lalić, B.; Komar, I. Problem of Boil-off in LNG Supply Chain. Trans. Marit. Sci. 2013, 2, 91-100. [CrossRef]

18. van Biert, L.; Godjevac, M.; Visser, K.; Aravind, P.V. A review of fuel cell systems for maritime applications. J. Power Sources 2016, 327, 345-364. [CrossRef]

19. Szilágyi, P.Á.; Serra-Crespo, P.; Gascon, J.; Geerlings, H.; Dam, B. The Impact of Post-Synthetic Linker Functionalization of MOFs on Methane Storage: The Role of Defects. Front. Energy Res. 2016, 4, 1-6. [CrossRef]

20. Liang, C.C.; Shi, Z.L.; He, C.T.; Tan, J.; Zhou, H.D.; Zhou, H.L.; Lee, Y.; Zhang, Y.B. Engineering of Pore Geometry for Ultrahigh Capacity Methane Storage in Mesoporous Metal-Organic Frameworks. J. Am. Chem. Soc. 2017, 139, 13300-13303. [CrossRef]

21. Chui, S.S.Y.; Lo, S.M.F.; Charmant, J.P.H.; Orpen, A.G.; Williams, I.D. A chemically functionalizable nanoporous material [Cu3(TMA)2 (H2O)3](n). Science 1999, 283, 1148-1150. [CrossRef] [PubMed]

22. Morris, R.E.; Wheatley, P.S. Gas storage in nanoporous materials. Angew. Chem. Int. Ed. 2008, 47, $4966-4981$. [CrossRef] [PubMed]

23. Menon, V.C.; Komarneni, S. Porous adsorbents for vehicular natural gas storage: A review. J. Porous Mater. 1998, 5, 43-58. [CrossRef]

24. Makal, T.A.; Li, J.-R.; Lu, W.; Zhou, H.-C. Methane storage in advanced porous materials. Chem. Soc. Rev. 2012, 41, 7761-7779. [CrossRef] [PubMed] 
25. Hamza, U.D.; Nasri, N.S.; Mohammed, J.; Majid, Z.A. Natural gas adsorption on biomass derived activated carbons: A mini review. MATEC Web Conf. 2016, 60, 1-5. [CrossRef]

26. Sircar, S.; Golden, T.C.; Rao, M.B. Activated carbon for gas separation and storage. Carbon N. Y. 1996, 34, 1-12. [CrossRef]

27. Matranga, K.R.; Myers, A.L.; Glandt, E.D. Storage of Natural-Gas By Adsorption on Activated Carbon. Chem. Eng. Sci. 1992, 47, 1569-1579. [CrossRef]

28. Himeno, S.; Komatsu, T.; Fujita, S. High-Pressure Adsorption Equilibria of Methane and Carbon Dioxide on Several Activated Carbons. J. Chem. Eng. Data 2005, 50, 369-376. [CrossRef]

29. Noro, S.; Kitagawa, S.; Kondo, M.; Seki, K. A New, Methane Adsorbent, Porous Coordination Polymer [\{CuSiF6 (4, 4'-bipyridine)2\}n]. Angew. Chemie Int. Ed. 2000, 39, 2081-2084. [CrossRef]

30. Yaghi, O.M.; O'Keeffe, M.; Ockwig, N.W.; Chae, H.K.; Eddaoudi, M.; Kim, J. Reticular synthesis and the design of new materials. Nature 2003, 423, 705-714. [CrossRef]

31. Furukawa, H.; Ko, N.; Go, Y.B.; Aratani, N.; Choi, S.B.; Choi, E.; Yazaydin, A.Ö.; Snurr, R.Q.; O’Keeffe, M.; Kim, J.; et al. Ultrahigh porosity in metal-organic frameworks. Science 2010, 329, 424-428. [CrossRef] [PubMed]

32. Perry, J.J.; Perman, J.A.; Zaworotko, M.J. Design and synthesis of metal-organic frameworks using metal-organic polyhedra as supermolecular building blocks. Chem. Soc. Rev. 2009, 38, 1400-1417. [CrossRef] [PubMed]

33. ARPA-E | MOVE. Available online: https://arpa-e.energy.gov/?q=arpa-e-programs/move (accessed on 18 August 2018).

34. Guo, Z.; Wu, H.; Srinivas, G.; Zhou, Y.; Xiang, S.; Chen, Z.; Yang, Y.; Zhou, W.; O'Keeffe, M.; Chen, B. A metal-organic framework with optimized open metal sites and pore spaces for high methane storage at room temperature. Angew. Chem. Int. Ed. 2011, 50, 3178-3181. [CrossRef] [PubMed]

35. Liu, L.; Konstas, K.; Hill, M.R.; Telfer, S.G. Programmed pore architectures in modular quaternary metal-organic frameworks. J. Am. Chem. Soc. 2013, 135, 17731-17734. [CrossRef] [PubMed]

36. Nguyen, N.T.T.; Furukawa, H.; Gándara, F.; Nguyen, H.T.; Cordova, K.E.; Yaghi, O.M. Selective capture of carbon dioxide under humid conditions by hydrophobic chabazite-type zeolitic imidazolate frameworks. Angew. Chem. Int. Ed. 2014, 53, 10645-10648. [CrossRef] [PubMed]

37. Almeida Paz, F.A.; Klinowski, J.; Vilela, S.M.F.; Tomé, J.P.C.; Cavaleiro, J.A.S.; Rocha, J. Ligand design for functional metal-organic frameworks. Chem. Soc. Rev. 2012, 41, 1088-1110. [CrossRef] [PubMed]

38. Zhao, D.; Timmons, D.J.; Yuan, D.; Zhou, H.C. Tuning the topology and functionality of metal-organic frameworks by ligand design. Acc. Chem. Res. 2011, 44, 123-133. [CrossRef] [PubMed]

39. Wang, C.; Liu, D.; Lin, W. Metal-organic frameworks as a tunable platform for designing functional molecular materials. J. Am. Chem. Soc. 2013, 135, 13222-13234. [CrossRef] [PubMed]

40. Stock, N.; Biswas, S. Synthesis of metal-organic frameworks (MOFs): Routes to various MOF topologies, morphologies, and composites. Chem. Rev. 2012, 112, 933-969. [CrossRef]

41. Horcajada, P.; Serre, C.; Vallet-Regí, M.; Sebban, M.; Taulelle, F.; Férey, G. Metal-organic frameworks as efficient materials for drug delivery. Angew. Chem. Int. Ed. 2006, 45, 5974-5978. [CrossRef]

42. Taylor, M.K.; Runčevski, T.; Oktawiec, J.; Gonzalez, M.I.; Siegelman, R.L.; Mason, J.A.; Ye, J.; Brown, C.M.; Long, J.R. Tuning the Adsorption-Induced Phase Change in the Flexible Metal-Organic Framework Co(bdp). J. Am. Chem. Soc. 2016, 138, 15019-15026. [CrossRef] [PubMed]

43. Deng, H.; Grunder, S.; Cordova, K.E.; Valente, C.; Furukawa, H.; Hmadeh, M.; Gándara, F.; Whalley, A.C.; Liu, Z.; Asahina, S.; et al. Large-pore apertures in a series of metal-organic frameworks. Science 2012, 336, 1018-1023. [CrossRef] [PubMed]

44. Li, H.; Eddaoudi, M.; O'Keeffe, M.; Yaghi, O.M. Design and synthesis of an exceptionally stable and highly porous metal-organic framework. Nature 1999, 402, 276-279. [CrossRef]

45. Furukawa, H.; Cordova, K.E.; O'Keeffe, M.; Yaghi, O.M. The chemistry and applications of metal-organic frameworks. Science 2013, 341, 1-12. [CrossRef] [PubMed]

46. Peng, Y.; Krungleviciute, V.; Eryazici, I.; Hupp, J.T.; Farha, O.K.; Yildirim, T. Methane storage in metal-organic frameworks: Current records, surprise findings, and challenges. J. Am. Chem. Soc. 2013, 135, 11887-11894. [CrossRef] [PubMed]

47. Gándara, F.; Furukawa, H.; Lee, S.; Yaghi, O.M. High methane storage capacity in aluminum metal-organic frameworks. J. Am. Chem. Soc. 2014, 136, 5271-5274. [CrossRef] [PubMed] 
48. Li, B.; Wen, H.M.; Wang, H.; Wu, H.; Yildirim, T.; Zhou, W.; Chen, B. Porous metal-organic frameworks with Lewis basic nitrogen sites for high-capacity methane storage. Energy Environ. Sci. 2015, 8, $2504-2511$. [CrossRef]

49. Moellmer, J.; Moeller, A.; Dreisbach, F.; Glaeser, R.; Staudt, R. High pressure adsorption of hydrogen, nitrogen, carbon dioxide and methane on the metal-organic framework HKUST-1. Microporous Mesoporous Mater. 2011, 138, 140-148. [CrossRef]

50. Vikrant, K.; Kumar, V.; Kim, K.H.; Kukkar, D. Metal-organic frameworks (MOFs): Potential and challenges for capture and abatement of ammonia. J. Mater. Chem. A 2017, 5, 22877-22896. [CrossRef]

51. Yan, Y.; Kolokolov, D.I.; Da Silva, I.; Stepanov, A.G.; Blake, A.J.; Dailly, A.; Manuel, P.; Tang, C.C.; Yang, S.; Schröder, M. Porous Metal-Organic Polyhedral Frameworks with Optimal Molecular Dynamics and Pore Geometry for Methane Storage. J. Am. Chem. Soc. 2017, 139, 13349-13360. [CrossRef]

52. Gómez-Gualdrón, D.A.; Wilmer, C.E.; Farha, O.K.; Hupp, J.T.; Snurr, R.Q. Exploring the limits of methane storage and delivery in nanoporous materials. J. Phys. Chem. C 2014, 118, 6941-6951. [CrossRef]

53. Getman, R.B.; Bae, Y.-S.; Wilmer, C.E.; Snurr, R.Q. Review and Analysis of Molecular Simulations of Methane, Hydrogen, and Acetylene Storage in Metal-Organic Frameworks. Chem. Rev. 2012, 112, 703-723. [CrossRef] [PubMed]

54. Zhou, H.C.; Long, J.R.; Yaghi, O.M. Introduction to metal-organic frameworks. Chem. Rev. 2012, 112, $673-674$. [CrossRef] [PubMed]

55. Long, J.R.; Yaghi, O.M. The pervasive chemistry of metal-organic frameworks. Chem. Soc. Rev. 2009, 38, 1213-1214. [CrossRef] [PubMed]

56. James, S.L. Metal-organic frameworks. Chem. Soc. Rev. 2003, 32, 276-288. [CrossRef] [PubMed]

57. Cohen, S.M. Postsynthetic methods for the functionalization of metal-organic frameworks. Chem. Rev. 2012, 112, 970-1000. [CrossRef] [PubMed]

58. He, Y.; Zhou, W.; Qian, G.; Chen, B. Methane storage in metal-organic frameworks. Chem. Soc. Rev. 2014, 43, 5657-5678. [CrossRef] [PubMed]

59. Farha, O.K.; Hupp, J.T. Rational design, synthesis, purification, and activation of metal-organic framework materials. Acc. Chem. Res. 2010, 43, 1166-1175. [CrossRef] [PubMed]

60. Wang, Z.; Cohen, S.M. Postsynthetic modification of metal-organic frameworks. Chem. Soc. Rev. 2009, 38, 1315-1329. [CrossRef]

61. Mason, J.A.; Veenstra, M.; Long, J.R. Evaluating metal-organic frameworks for natural gas storage. Chem. Sci. 2014, 5, 32-51. [CrossRef]

62. Li, B.; Wen, H.M.; Zhou, W.; Xu, J.Q.; Chen, B. Porous Metal-Organic Frameworks: Promising Materials for Methane Storage. Chem 2016, 1,557-580. [CrossRef]

63. Li, H.; Wang, K.; Sun, Y.; Lollar, C.T.; Li, J.; Zhou, H.C. Recent advances in gas storage and separation using metal-organic frameworks. Mater. Today 2018, 21, 108-121. [CrossRef]

64. Lin, Y.; Kong, C.; Zhang, Q.; Chen, L. Metal-Organic Frameworks for Carbon Dioxide Capture and Methane Storage. Adv. Energy Mater. 2017, 7, 1601296. [CrossRef]

65. Howarth, A.J.; Liu, Y.; Li, P.; Li, Z.; Wang, T.C.; Hupp, J.T.; Farha, O.K. Chemical, thermal and mechanical stabilities of metal-organic frameworks. Nat. Rev. Mater. 2016, 1, 1-15. [CrossRef]

66. Babaei, H.; McGaughey, A.J.H.; Wilmer, C.E. Transient Mass and Thermal Transport during Methane Adsorption into the Metal-Organic Framework HKUST-1. ACS Appl. Mater. Interfaces 2018, 10, 2400-2406. [CrossRef]

67. Prajwal, B.P.; Ayappa, K.G. Evaluating methane storage targets: From powder samples to onboard storage systems. Adsorption 2014, 20, 769-776. [CrossRef]

68. Chang, K.J.; Talu, O. Behavior and performance of adsorptive natural gas storage cylinders during discharge. Appl. Therm. Eng. 1996, 16, 359-374. [CrossRef]

69. Babaei, H.; Wilmer, C.E. Mechanisms of Heat Transfer in Porous Crystals Containing Adsorbed Gases: Applications to Metal-Organic Frameworks. Phys. Rev. Lett. 2016, 116, 025902. [CrossRef]

70. Kloutse, F.A.; Zacharia, R.; Cossement, D.; Chahine, R. Specific heat capacities of MOF-5, Cu-BTC, Fe-BTC, MOF-177 and MIL-53 (Al) over wide temperature ranges: Measurements and application of empirical group contribution method. Microporous Mesoporous Mater. 2015, 217, 1-5. [CrossRef]

71. Mu, B.; Walton, K.S. Thermal analysis and heat capacity study of metal-organic frameworks. J. Phys. Chem. C 2011, 115, 22748-22754. [CrossRef] 
72. Babaei, H.; McGaughey, A.J.H.; Wilmer, C.E. Effect of pore size and shape on the thermal conductivity of metal-organic frameworks. Chem. Sci. 2016, 8, 583-589. [CrossRef] [PubMed]

73. Sezginel, K.B.; Asinger, P.A.; Babaei, H.; Wilmer, C.E. Thermal Transport in Interpenetrated Metal-Organic Frameworks. Chem. Mater. 2018, 30, 2281-2286. [CrossRef]

74. Mason, J.A.; Oktawiec, J.; Taylor, M.K.; Hudson, M.R.; Rodriguez, J.; Bachman, J.E.; Gonzalez, M.I.; Cervellino, A.; Guagliardi, A.; Brown, C.M.; et al. Methane storage in flexible metal-organic frameworks with intrinsic thermal management. Nature 2015, 527, 357-361. [CrossRef] [PubMed]

75. Loiseau, T.; Serre, C.; Huguenard, C.; Fink, G.; Taulelle, F.; Henry, M.; Bataille, T.; Férey, G. A Rationale for the Large Breathing of the Porous Aluminum Terephthalate (MIL-53) Upon Hydration. Chem. Eur. J. 2004, 10, 1373-1382. [CrossRef] [PubMed]

76. Boutin, A.; Coudert, F.-X.; Springuel-Huet, M.-A.; Neimark, A.V.; Férey, G.; Fuchs, A.H. The behavior of flexible MIL-53(Al) upon CH 4 and CO 2 adsorption. J. Phys. Chem. C 2010, 114, 22237-22244. [CrossRef]

77. Huang, J.; Xia, X.; Hu, X.; Li, S.; Liu, K. A general method for measuring the thermal conductivity of MOF crystals. Int. J. Heat Mass Transf. 2019, 138, 11-16. [CrossRef]

78. Huang, B.L.; Ni, Z.; Millward, A.; McGaughey, A.J.H.; Uher, C.; Kaviany, M.; Yaghi, O. Thermal conductivity of a metal-organic framework (MOF-5): Part II. Measurement. Int. J. Heat Mass Transf. 2007, 50, 405-411. [CrossRef]

79. Bae, Y.S.; Snurr, R.Q. Optimal isosteric heat of adsorption for hydrogen storage and delivery using metal-organic frameworks. Microporous Mesoporous Mater. 2010, 132, 300-303. [CrossRef]

80. Rallapalli, P.; Patil, D.; Prasanth, K.P.; Somani, R.S.; Jasra, R.V.; Bajaj, H.C. An alternative activation method for the enhancement of methane storage capacity of nanoporous aluminium terephthalate, MIL-53(Al). J. Porous Mater. 2010, 17, 523-528. [CrossRef]

81. Bolinois, L.; Kundu, T.; Wang, X.; Wang, Y.; Hu, Z.; Koh, K.; Zhao, D. Breathing-induced new phase transition in an MIL-53(Al)-NH 2 metal-organic framework under high methane pressures. Chem. Commun. 2017, 53, 8118-8121. [CrossRef]

82. Deng, H.; Doonan, C.J.; Furukawa, H.; Ferreira, R.B.; Towne, J.; Knobler, C.B.; Wang, B.; Yaghi, O.M. Multiple functional groups of varying ratios in metal-organic frameworks. Science 2010, 327, 846-850. [CrossRef] [PubMed]

83. Wilmer, C.E.; Farha, O.K.; Yildirim, T.; Eryazici, I.; Krungleviciute, V.; Sarjeant, A.A.; Snurr, R.Q.; Hupp, J.T. Gram-scale, high-yield synthesis of a robust metal-organic framework for storing methane and other gases. Energy Environ. Sci. 2013, 6, 1158-1163. [CrossRef]

84. Peng, Y.; Srinivas, G.; Wilmer, C.E.; Eryazici, I.; Snurr, R.Q.; Hupp, J.T.; Yildirim, T.; Farha, O.K. Simultaneously high gravimetric and volumetric methane uptake characteristics of the metal-organic framework NU-111. Chem. Commun. 2013, 49, 2992-2994. [CrossRef] [PubMed]

85. He, Y.; Zhou, W.; Yildirim, T.; Chen, B. A series of metal-organic frameworks with high methane uptake and an empirical equation for predicting methane storage capacity. Energy Environ. Sci. 2013, 6, 2735-2744. [CrossRef]

86. Wen, H.-M.; Li, B.; Yuan, D.; Wang, H.; Yildirim, T.; Zhou, W.; Chen, B. A porous metal-organic framework with an elongated anthracene derivative exhibiting a high working capacity for the storage of methane. J. Mater. Chem. A 2014, 2, 11516-11522. [CrossRef]

87. Li, L.; Tang, S.; Wang, C.; Lv, X.; Jiang, M.; Wu, H.; Zhao, X. High gas storage capacities and stepwise adsorption in a $\mathrm{UiO}$ type metal-organic framework incorporating Lewis basic bipyridyl sites. Chem. Commun. 2014, 50, 2304-2307. [CrossRef] [PubMed]

88. Tian, T.; Velazquez-Garcia, J.; Bennett, T.D.; Fairen-Jimenez, D. Mechanically and chemically robust ZIF-8 monoliths with high volumetric adsorption capacity. J. Mater. Chem. A 2015, 3, 2999-3005. [CrossRef]

89. Tagliabue, M.; Rizzo, C.; Millini, R.; Dietzel, P.D.C.; Blom, R.; Zanardi, S. Methane storage on CPO-27-Ni pellets. J. Porous Mater. 2011, 18, 289-296. [CrossRef]

90. Tian, T.; Zeng, Z.; Vulpe, D.; Casco, M.E.; Divitini, G.; Midgley, P.A.; Silvestre-Albero, J.; Tan, J.C.; Moghadam, P.Z.; Fairen-Jimenez, D. A sol-gel monolithic metal-organic framework with enhanced methane uptake. Nat. Mater. 2018, 17, 174-179. [CrossRef]

91. Bazer-Bachi, D.; Assié, L.; Lecocq, V.; Harbuzaru, B.; Falk, V. Towards industrial use of metal-organic framework: Impact of shaping on the MOF properties. Powder Technol. 2014, 255, 52-59. [CrossRef] 
92. Rogge, S.M.J.; Waroquier, M.; Van Speybroeck, V. Reliably Modeling the Mechanical Stability of Rigid and Flexible Metal-Organic Frameworks. Acc. Chem. Res. 2018, 51, 138-148. [CrossRef]

93. Thornton, A.W.; Babarao, R.; Jain, A.; Trousselet, F.; Coudert, F.X. Defects in metal-organic frameworks: A compromise between adsorption and stability? Dalt. Trans. 2016, 45, 4352-4359. [CrossRef]

94. Dissegna, S.; Vervoorts, P.; Hobday, C.L.; Düren, T.; Daisenberger, D.; Smith, A.J.; Fischer, R.A.; Kieslich, G. Tuning the Mechanical Response of Metal-Organic Frameworks by Defect Engineering. J. Am. Chem. Soc. 2018, 140, 11581-11584. [CrossRef]

95. Burtch, N.C.; Heinen, J.; Bennett, T.D.; Dubbeldam, D.; Allendorf, M.D. Mechanical Properties in Metal-Organic Frameworks: Emerging Opportunities and Challenges for Device Functionality and Technological Applications. Adv. Mater. 2018, 30, 1704124. [CrossRef]

96. Dürholt, J.P.; Keupp, J.; Schmid, R. The Impact of Mesopores on the Mechanical Stability of HKUST-1: A Multiscale Investigation. Eur. J. Inorg. Chem. 2016, 2016, 4517-4523. [CrossRef]

97. Yot, P.G.; Yang, K.; Ragon, F.; Dmitriev, V.; Devic, T.; Horcajada, P.; Serre, C.; Maurin, G. Exploration of the mechanical behavior of metal organic frameworks UiO-66(Zr) and MIL-125(Ti) and their NH2 functionalized versions. Dalt. Trans. 2016, 45, 4283-4288. [CrossRef]

98. Moosavi, S.M.; Boyd, P.G.; Sarkisov, L.; Smit, B. Improving the Mechanical Stability of Metal-Organic Frameworks Using Chemical Caryatids. ACS Cent. Sci. 2018, 4, 832-839. [CrossRef]

99. Veluswamy, H.P.; Kumar, A.; Seo, Y.; Lee, J.D.; Linga, P. A review of solidified natural gas (SNG) technology for gas storage via clathrate hydrates. Appl. Energy 2018, 262-285. [CrossRef]

100. Sun, Y.; Liu, C.; Su, W.; Zhou, Y.; Zhou, L. Principles of methane adsorption and natural gas storage. Adsorption 2009, 15, 133-137. [CrossRef]

101. Zhang, H.; Deria, P.; Farha, O.K.; Hupp, J.T.; Snurr, R.Q. A thermodynamic tank model for studying the effect of higher hydrocarbons on natural gas storage in metal-organic frameworks. Energy Environ. Sci. 2015, 8, 1501-1510. [CrossRef]

102. Wu, Y.; Tang, D.; Verploegh, R.J.; Xi, H.; Sholl, D.S. Impacts of Gas Impurities from Pipeline Natural Gas on Methane Storage in Metal-Organic Frameworks during Long-Term Cycling. J. Phys. Chem. C 2017, 121, 15735-15745. [CrossRef]

103. Zhang, M.; Zhou, W.; Pham, T.; Forrest, K.A.; Liu, W.; He, Y.; Wu, H.; Yildirim, T.; Chen, B.; Space, B.; et al. Fine Tuning of MOF-505 Analogues To Reduce Low-Pressure Methane Uptake and Enhance Methane Working Capacity. Angew. Chem. Int. Ed. 2017, 56, 11426-11430. [CrossRef]

104. Romanos, J.; Rash, T.; Abou Dargham, S.; Prosniewski, M.; Barakat, F.; Pfeifer, P. Cycling and Regeneration of Adsorbed Natural Gas in Microporous Materials. Energy Fuels 2017, 31, 14332-14337. [CrossRef]

105. Jacoby, M. Heading to Market with MOFs. Chem. Eng. News 2010, 86, 13-16. [CrossRef]

106. BASF Metal Organic Frameworks (MOFs): Innovative Fuel Systems for Natural Gas Vehicles (NGVs). Chem. Soc. Rev. 2014, 43, 6173-6174. [CrossRef]

107. BASF to Showcase Metal Organic Frameworks (MOFs) for Energy Storage at NGV Americas Conference. Available online: https://www.basf.com/us/en/media/news-releases/2013/11/p-13-452.html (accessed on 1 July 2019).

108. Scott, A. Round Two for MOF Commercialization. Available online: https://cen.acs.org/articles/95/i24/Roundtwo-MOF-commercialization.html (accessed on 1 August 2019).

109. Green Science Alliance Co., Ltd. Has Started the Manufacturing and Custom Synthesis of a Metal Organic Framework (MOF), Porous Coordination Polymers (PCPs). Available online: https://www.prnewswire. com/news-releases/green-science-alliance-co-ltd-has-started-the-manufacturing-and-custom-synthesisof-a-metal-organic-framework-mof-porous-coordination-polymers-pcps-300644297.html (accessed on 1 August 2019).

110. McMahon, M.M. NuMat Brings First MOF-Enabled Gas Storage Product to Market | Institute for Sustainability and Energy at Northwestern (ISEN). Available online: https://isen.northwestern.edu/numat-brings-firstmof-enabled-gas-storage-product-to-market (accessed on 1 August 2019).

111. Mueller, U.; Schubert, M.; Teich, F.; Puetter, H.; Schierle-Arndt, K.; Pastré, J. Metal-organic frameworks-prospective industrial applications. J. Mater. Chem. 2006, 16, 626-636. [CrossRef]

112. Rubio-Martinez, M.; Avci-Camur, C.; Thornton, A.W.; Imaz, I.; Maspoch, D.; Hill, M.R. New synthetic routes towards MOF production at scale. Chem. Soc. Rev. 2017, 46, 3453-3480. [CrossRef] 
113. DeSantis, D.; Mason, J.A.; James, B.D.; Houchins, C.; Long, J.R.; Veenstra, M. Techno-economic Analysis of Metal-Organic Frameworks for Hydrogen and Natural Gas Storage. Energy E Fuels 2017, 31, 2024-2032.

114. Rubio-Martinez, M.; Batten, M.P.; Polyzos, A.; Carey, K.C.; Mardel, J.I.; Lim, K.S.; Hill, M.R. Versatile, high quality and scalable continuous flow production of metal-organic frameworks. Sci. Rep. 2014, 4, 1-5. [CrossRef]

115. Dunne, P.W.; Walton, R.I. Towards scalable and controlled synthesis of metal-organic framework materials using continuous flow reactors. Reaction Chem. Eng. 2016, 1, 352-360. [CrossRef]

116. Gaab, M.; Trukhan, N.; Maurer, S.; Gummaraju, R.; Müller, U. The progression of Al-based metal-organic frameworks-From academic research to industrial production and applications. Microporous Mesoporous Mater. 2012, 157, 131-136. [CrossRef]

117. Silva, P.; Vilela, S.M.F.; Tomé, J.P.C.; Almeida Paz, F.A. Multifunctional metal-organic frameworks: From academia to industrial applications. Chem. Soc. Rev. 2015, 44, 6774-6803. [CrossRef]

118. Julien, P.A.; Mottillo, C.; Friščić, T. Metal-organic frameworks meet scalable and sustainable synthesis. Green Chem. 2017, 19, 2729-2747. [CrossRef]

119. Witman, M.; Ling, S.; Jawahery, S.; Boyd, P.G.; Haranczyk, M.; Slater, B.; Smit, B. The Influence of Intrinsic Framework Flexibility on Adsorption in Nanoporous Materials. J. Am. Chem. Soc. 2017, 139, 5547-5557. [CrossRef]

(C) 2019 by the authors. Licensee MDPI, Basel, Switzerland. This article is an open access article distributed under the terms and conditions of the Creative Commons Attribution (CC BY) license (http://creativecommons.org/licenses/by/4.0/). 